\title{
LAURA MELOSI, Letteratura e civiltà, un paradigma della ricerca al Centro Romantico (con un caso di studio: Balzac)
}

\section{Marco Stupazzoni}

\section{(2) OpenEdition}

\section{Journals}

\section{Edizione digitale}

URL: http://journals.openedition.org/studifrancesi/16524

DOI: 10.4000/studifrancesi. 16524

ISSN: 2421-5856

\section{Editore}

Rosenberg \& Sellier

\section{Edizione cartacea}

Data di pubblicazione: 1 juillet 2019

Paginazione: 174

ISSN: 0039-2944

\section{Notizia bibliografica digitale}

Marco Stupazzoni, «LAURA melosı, Letteratura e civiltà, un paradigma della ricerca al Centro Romantico (con un caso di studio: Balzac)», Studi Francesi [Online], 187 (LXIII | I) | 2019, online dal 01 juillet 2019, consultato il 25 janvier 2021. URL: http://journals.openedition.org/studifrancesi/16524 ; DOI: https:// doi.org/10.4000/studifrancesi.16524

Questo documento è stato generato automaticamente il 25 janvier 2021.

\section{(c) $(1) \odot$}

Studi Francesi è distribuita con Licenza Creative Commons Attribuzione - Non commerciale - Non opere derivate 4.0 Internazionale. 


\title{
LAURA MELOSI, Letteratura e civiltà, un paradigma della ricerca al Centro Romantico (con un caso di studio: Balzac)
}

\author{
Marco Stupazzoni
}

\section{NOTIZIA}

LAURA MELOSI, Letteratura e civiltà, un paradigma della ricerca al Centro Romantico (con un caso di studio: Balzac), in Maurizio Bossi. Curiosità, conoscenza, impegno civile. Atti della giornata di studi, Firenze, 21 aprile 2017, Firenze, Olschki, 2017, «Gabinetto Scientifico Letterario G. P. Vieusseux. Studi» 28, pp. 25-37.

1 Per meglio delineare e valutare l'impatto dei testi letterarî in un determinato contesto storico, geografico e civile, risulta indispensabile riflettere non soltanto sulle caratteristiche del sistema di produzione e sulle modalità di circolazione dei testi nell'ambito di uno specifico mercato editoriale, ma, contemporaneamente, soffermarsi a valutare le «modalità con cui la lettura popolare li metabolizza» (p. 30).

Da questo punto di vista, la ricomposizione del quadro (locale e fiorentino, in particolare) relativo alla presenza e alla ricezione delle opere di Balzac, possedute e catalogate dal Gabinetto Scientifico e Letterario G. P. Vieusseux di Firenze, attraverso il prestito librario a domicilio consente a Laura Melosi di gettare nuova luce sulla fortuna (concreta) dei romanzi balzachiani nell'Ottocento, al di là della loro ricezione critica, fino almeno al 1863. Attraverso un'indagine dettagliata e rigorosa dei "Libri del prestito", e con un controllo attento dell'andamento dei prestiti, l'A. ci informa che «i titoli di Balzac nel periodo considerato ammontano complessivamente a 39, comprese le traduzioni» (p. 35). Di questi 39 titoli, 19 sono prime edizioni francesi (ma l'A. inserisce in questo elenco anche alcune 'contrefaçons belges'), a cui si aggiungono 
l'edizione delle CEuvres complètes (Furne, 1842-1845), quella pubblicata circa un decennio dopo da Houssiaux, alcune traduzioni inglesi, sei traduzioni italiane edite tra il $1834 \mathrm{e}$ il 1846 e altre edizioni di romanzi, soprattutto belghe.

3 Particolarmente favorevole è risultato il successo, presso il pubblico dei lettori, de La Physiologie du mariage (Ollivier, 1832), opera che si colloca senza ombra di dubbio al primo posto di questa classifica di gradimento; molto richieste sono risultate opere quali: Le dernier chouan ou la Bretagne en 1800 (Canel, 1829), La Peau de chagrin (Gosselin, 1831), i Contes drolatiques (Bruxelles, Hauman, 1833), le Scènes de la vie privée, de la vie de province e de la vie parisienne (Furne). Scarso interesse sembrano aver ottenuto, al contrario, le Scènes de la vie militaire e de la vie de campagne, le Études philosophiques e L'Interdiction. 